\title{
Editorial
}

\section{Announcing the Digital Edition of AI Magazine}

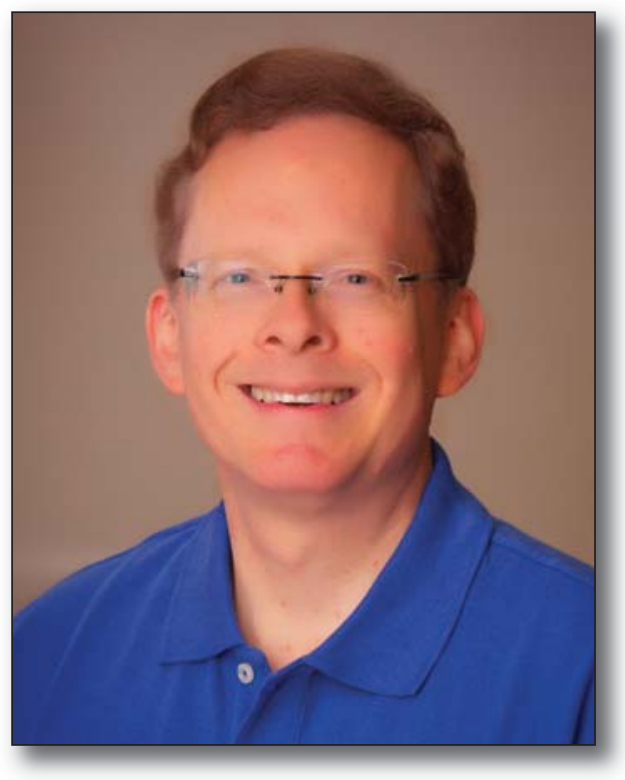

A s tablets and other mobile devices have become prevalent, AI Magazine has been investigating methods for making the magazine available in digital form in addition to printed form, to serve varied reader preferences and provide new capabilities. I am delighted to announce that this project has come to fruition with the launch of the digital edition of $A I$ Magazine.

As each issue of the magazine is published, its digital edition will be delivered to subscribers by e-mail. The digital edition is browser-based, making it accessible via the web, smartphone, or any modern web-enabled device. It provides the ability to quickly search, save, and share articles, as well as convenient options for navigating the magazine and seamlessly linking to other resources. The digital edition will enable substantial advances in the magazine's future design, such as the use of color throughout and the inclusion of embedded video, and over time the magazine will increasingly exploit this potential.

Special thanks for this milestone are due to managing editor Mike Hamilton, whose vision, expertise, and effort have brought AI Magazine's digital edition into being, and who will guide the design transition to fully exploit the digital edition's capabilities.

I encourage you to explore the digital edition and hope you enjoy this this additional way to read AI Magazine!

\footnotetext{
- David Leake Editor-in-Chief AI Magazine
} 